\title{
Diurnal variation and repeatability of arterial stiffness and cardiac output measurements in the third trimester of uncomplicated pregnancy
}

Mohamed Waseem OSMAN ${ }^{1}$, Francesca LEONE ${ }^{2}$, Mintu NATH ${ }^{3}$, Asma KHALIL ${ }^{4}$, David R WEBB ${ }^{5}$, Thompson G. ROBINSON ${ }^{6}$, Hatem A. MOUSA ${ }^{7}$

${ }^{1}$ Clinical Research Fellow, University Hospitals of Leicester, mwo3@le.ac.uk

${ }^{2}$ Medical Student, University of Leicester, f163@student.le.ac.uk

${ }^{3}$ Senior Biomedical Statistician, University Hospitals of Leicester, mn193@leicester.ac.uk

${ }^{4}$ Consultant/ Reader in Maternal and Fetal Medicine, St George's University of London, akhalil@sgul.ac.uk

${ }^{5}$ Senior Lecturer/Associate Professor and Honorary Consultant Physician in Diabetes Medicine, Diabetes Research Centre, University of Leicester, david.webb@uhl-tr.nhs.uk

${ }^{6}$ Professor of Stroke Medicine, Department of Cardiovascular Sciences and NIHR Leicester Biomedical Research Centre, University of Leicester, tgr2@le.ac.uk

${ }^{7}$ Consultant/ Honorary Senior Lecturer in Maternal and Fetal Medicine, University of Leicester, tommy.mousa@uhl-tr.nhs.uk

Contact author address:

Dr M.W Osman

University Hospitals of Leicester

Leicester Royal Infirmary

Infirmary Close

LE1 5WW

Mwo3@le.ac.uk 
Short title: Diurnal variation and repeatability of maternal haemodynamic parameters

Keywords: Arterial stiffness, maternal haemodynamics, cardiac output, diurnal variation, repeatability

Word count of manuscript including references, legends, tables: 4743 words

Word count of abstract: 415 words

Total number of figures: 3

Total number of tables: 3 


\section{ABSTRACT}

\section{Aim}

To investigate same day repeated measures and diurnal variation of arterial stiffness, cardiac output (CO), stroke volume (SV) and total peripheral resistance (TPR) during the third trimester of normal pregnancy.

\section{Methodology}

Pulse wave velocity (PWV) and augmentation index (Alx) were recorded using the Arteriograph ${ }^{\circledast}$, while CO, SV and TPR were recorded using NICOM $^{\circledast}$. The measurements were obtained in the third trimester of pregnancy from 21 healthy pregnant women at four time points (morning, afternoon, evening and midnight) over a $24 \mathrm{~h}$ period. Triplicate measurements of 67 women were obtained at five-minute intervals to assess repeatability between measurements within a subject.

\section{Results}

Diurnal measurements of arterial stiffness for brachial Alx, aortic Alx and PWV were not statistically significantly different at any of the four time points. Estimated means (standard deviation) for PWV at the four stated time points were 7.81 (2.05), 8.45 (1.68), 7.87 (1.74) and $7.64 \mathrm{~m} / \mathrm{s}(1.15)$, respectively, $(p=0.267)$. Estimates for Alx at those time points were 10.22 (15.62), 4.44 (10.07), 6.49 (10.92) and $8.40 \%(8.16)$, respectively, $(p=0.295)$. Similarly, Mean Arterial Pressure (MAP), Stroke Volume (SV), Stroke Volume Index (SVI) and Total Peripheral Resistance (TPR) did not show any evidence of diurnal variation. However, we observed that the mean Cardiac Output (CO), Cardiac Index (CI) and Heart Rate (HR) varied 
from morning to midnight; the mean $\mathrm{CO}, \mathrm{HR}$ and $\mathrm{Cl}$ increased significantly in the afternoon compared with the corresponding mean morning measurements in a similar fashion to HR. Mean (standard deviation) CO estimates at the four stated time points were 5.90 (1.33), 6.38 (1.49), $6.18(1.43)$ and $5.80 \mathrm{ml} / \mathrm{min}(1.19)$, respectively $(p<0.001)$, while mean $\mathrm{Cl}$ estimates were $3.65(0.58), 3.93(0.68), 3.81(0.65)$, and $3.57(0.48)$, respectively $(p<0.001)$ and mean HR estimates were 95 (12), 98 (13), 95 (12) and 88 (12.98), respectively ( $p<0.001)$.

Triplicate measurements of 61 women in our repeatability study showed moderate to high correlation between observations on the same woman for all Arteriograph and NICOM variables (estimates of intraclass correlation ranged from 0.49 to 0.91 ).

\section{Conclusion}

With the exception of $\mathrm{CO}, \mathrm{Cl}$ and $\mathrm{HR}$ which showed a diurnal variation, measurements of most haemodynamic parameters did not change significantly from morning to midnight suggesting there was no evidence of systematic differences in the mean values of these variables at these time points. Multiple consecutive non-invasive measurements of vascular stiffness, CO, SV and TPR were highly correlated confirming repeatability of measurements in the third trimester of uncomplicated pregnancy, so these haemodynamic measurements do not need to be undertaken at a specific time period of the day. 


\section{INTRODUCTION}

The cardiovascular system undergoes positive adaptations during pregnancy. In normal pregnancy, arterial stiffness decreases during the first trimester and remains low until the end of pregnancy due to either reduced smooth muscle tone or vessel wall remodelling ${ }^{1,2}$. Furthermore, there is an increase in intravascular volume, cardiac output (CO), and heart rate $(H R)$, together with a decrease in vascular resistance and mean blood pressure (BP) from as early as six weeks gestation ${ }^{2-4}$. CO steadily increases from the first trimester of pregnancy to $45 \%$ above the non-pregnant level at 24 weeks of gestation, it then plateaus but remains elevated until term ${ }^{2}$, and is a consequence of increased HR and decreased systemic vascular resistance (SVR). From the $5^{\text {th }}$ week of pregnancy, there is a decline in SVR, which reaches a nadir between weeks 20 and 32 weeks $^{4,5}$, and is due to changes in resistance and flow in multiple vascular beds, such as the utero-placental unit. ${ }^{4}$ Thereafter, there is a gradual increase in SVR from 32 weeks until term ${ }^{4,5}$.

Increased systemic arterial stiffness has been reported among women with hypertensive disorders during pregnancy ${ }^{6-8}$, is associated with foetal growth restriction ${ }^{9}$, and may have a role as a potential screening tool in pregnancy ${ }^{10}$. Central arterial stiffening is associated with adverse cardiovascular outcomes in various patient groups ${ }^{11}$, as well as in the general population $^{12}$; associated increased pulse wave velocity (PWV) being an independent predictor of cardiovascular morbidity and mortality ${ }^{13-16}$. European Society of Hypertension guidelines propose that in arterial hypertension, PWV over $12 \mathrm{~m} / \mathrm{s}$ suggests sub-clinical organ damage ${ }^{17}$, though normal limits for PWV in pregnancy have not been reported. Furthermore, device manufacturers commonly state that it is necessary to standardise the time of the day when performing non-invasive cardiovascular assessments of arterial 
stiffness. However, previous studies of diurnal variability of arterial stiffness have been limited to healthy non-pregnant populations ${ }^{18-20}$ with inconsistent methodologies. Only one small $(n=15)$ study of diurnal variation in PWV used four time points and reported a lack of significant circadian rhythm changes ${ }^{20}$. In addition, the repeatability of PWV has only been assessed in non-pregnant women ${ }^{19,21,22}$. However, understanding the circadian pattern of maternal haemodynamics in normal pregnancy is crucial to both clinicians and researchers, as it may influence both the reliability and performance in screening for adverse pregnancy outcome. Therefore, the aim of the present study was to examine the repeatability of successive non-invasive cardiovascular measurements among pregnant women, and to assess diurnal haemodynamic changes in uncomplicated pregnancy.

\section{METHODS}

\section{Non-invasive Cardiovascular Assessment}

The arterial stiffness measurements were obtained using a commercially available, validated platform that use established methodology, tried and tested in clinical populations, the Arteriograph ${ }^{\oplus}$. CO measurements were obtained using the Non-Invasive Cardiac Output Monitor (NICOM, Cheetah Medical, Portland, Oregon). In addition to values for CO including HR and stroke volume (SV), the NICOM device calculates the SV index (SVI), CO, the total peripheral resistance (TPR) and BP.

Three professionals who received appropriate training in the use of the Arteriograph ${ }^{\circledR}$ and the $\mathrm{NICOM}^{\circledR}$ devices recorded all data. Both devices were automated and this therefore reduced the risk of inter-observer variability. 
Both studies were approved by the Stanmore National Research Ethics committee. Written informed consent was obtained from all participating women before their enrolment.

\section{Diurnal Variation}

Twenty-one low-risk pregnant women were recruited. Participants were excluded if they had one or more of the following conditions: a BMI $>25 \mathrm{~kg} / \mathrm{m}^{2}$ at booking, multiple pregnancy, foetal anomalies, essential hypertension, pregnancy-induced hypertension, preeclampsia, pregnancy complicated with foetal growth restriction or small for gestational age, thyroid disease requiring medication, renal disease, diabetes mellitus or on any medication that could affect BP. Participants were inpatients at the hospital for the duration of the study.

Participants were investigated at four time points during a 24-hour cycle: morning (between 0900 to $1000 \mathrm{~h})$, afternoon (1400-1500h), evening (2000-2100h), and midnight (00000100h). Participants were assessed in a temperature-controlled room $\left(22^{\circ} \mathrm{C}\right)$ in a semirecumbent position on their hospital bed, more than 45 minutes after food intake, and having avoided caffeine and alcohol for 24 hours. Participants rested for a minimum of ten minutes prior to the non-invasive haemodynamic examination and did not speak or move when the measurements were being undertaken.

\section{Repeatability study}

Sixty-seven women were recruited. The same exclusion criteria as those mentioned above were applied. Participants were assessed in a temperature-controlled room $\left(22^{\circ} \mathrm{C}\right)$ in a semirecumbent position on a hospital bed at the antenatal clinic. Participants rested for a minimum of ten minutes prior to non-invasive haemodynamic examination. Thereafter, 
three repeated non-invasive cardiovascular measurements at five-minute intervals were recorded. Participants were asked not to speak or move when the measurements were being undertaken.

\section{Statistical analysis}

Data from the diurnal study on the different Arteriograph ${ }^{\circledR}$ and $\mathrm{NICOM}^{\circledR}$ variables, measured on 21 pregnant women during the third trimester of pregnancy at four different time points (morning, afternoon, evening and midnight), were analysed using a linear mixed model incorporating time as a fixed effect and individual patient as a random effect.

Data from the repeatability study $(n=67)$ were analysed using a separate linear mixed model for each of the Arteriograph ${ }^{\circledR}$ and $\mathrm{NICOM}^{\circledR}$ variables. The model incorporated time as fixed effects and individual patient as a random effect.

To assess the correlation between observations on the same patient for both studies, we estimated the intra-class correlation (ICC) coefficient as the ratio of between patient variability to the overall variability and obtained $95 \%$ confidence interval of ICC by sampling the data using the bootstrap-based approach. A predictor was considered statistically significant if the two-sided type I error rate was less than $5 \%$ (i.e. $p<0.05$ ). All statistical analyses were carried out using the R software version 3.3 with appropriate $R$ packages ${ }^{23}(\mathrm{R}$ Core Team, 2016). 


\section{RESULTS}

\section{DIURNAL VARIATION}

Twenty-one low risk pregnant women of mean age $28.95(S D=6.38)$ years with a mean gestational age of 34 (3.74) weeks fulfilled our inclusion and exclusion criteria and agreed to participate in the study. Demographic details of the study population are summarised in Table 1. The mean values of arterial stiffness, at four time points (morning, afternoon, evening and midnight), are presented in Table 2, and individual measurements at these time points with the corresponding box plots are presented in Figure 1. There were nonsignificant reductions in brachial and aortic augmentation index (Alx) values from the morning to evening with increases afterwards, though PWV values increased nonsignificantly in the afternoon before decreasing later (Table 2).

The mean values of non-invasive $\mathrm{CO}$ variables using $\mathrm{NICOM}^{\circledR}$ are presented in Table 2 , with individual measurements in Figure 1. Among cardiac output variables measured, Mean Arterial Pressure (MAP), SV, SVI and TPR did not show any evidence of diurnal variation between four time points in pregnant women in their third trimester. However, we observed that the mean $\mathrm{CO}$, Cardiac Index $(\mathrm{Cl})$ and $\mathrm{HR}$ varied from morning to midnight; the mean $\mathrm{CO}, \mathrm{HR}$ and $\mathrm{Cl}$ increased significantly in the afternoon compared with the corresponding mean morning measurements in a similar fashion to HR.

ICC estimates between measurements on the same subject showed excellent or good correlation for NICOM variables while all the Arteriograph ${ }^{\circledR}$ variables showed fair estimates of ICC (Table 3). A moderate to higher estimate of ICC suggests higher between-patient variability and lower within-patient variability. 


\section{REPEATABILITY STUDY}

Sixty-seven women, of mean (SD) age 31.57 (6.09) years at a mean gestational age of 27.70 (2.29) weeks participated in the study to assess the repeatability of successive measurements of the Arteriograph ${ }^{\circledast}$ and $\mathrm{NICOM}^{\circledR}$ variables.

Outcomes from the linear mixed models showed no evidence $(p>0.14)$ that mean values of Arteriograph (Alx and PWV) and NICOM (CO, Cl, SV, SVI) differed at three successive measurements taken five minutes apart as evidenced by Table 3. Most variables showed approximately 0.2 to $1.9 \%$ changes in consecutive measurements.

ICC estimates between measurements on the same subject showed excellent correlation for NICOM variables, with the exception of stroke volume variation, where correlation was good. For the Arteriograph ${ }^{\circledast}$ variables, aortic PWV exhibited excellent ICC, and aortic Alx $\operatorname{good}($ Table 3).

Triplicate measurements on each subject of Arteriograph ${ }^{\circledast}$ and $\mathrm{NICOM}^{\circledR}$ variables are presented graphically in Figure 2. Triplicate measurements on the same patient are joined by dotted lines to demonstrate the consistency in repeatable measurements for each patient. We also presented individual values along with box plots at each measurement points (Figure 3) illustrating similar central tendencies across three successive measurements $(1,2,3)$ for each subject. 


\section{DISCUSSION}

To the best of our knowledge, this is the first study to investigate diurnal variation and the repeatability of measurements of arterial stiffness and CO among women during their third trimester of pregnancy. There was no evidence of significant diurnal variability for the majority of arterial stiffness and CO parameters studied, with the exception of $\mathrm{CO}$ and $\mathrm{Cl}$. Furthermore, measurements of vascular stiffness and CO were repeatable, with good to excellent ICC estimates.

Findings of non-significant diurnal variation of PWV and Alx reaffirm the previous work carried out in non-pregnant population ${ }^{18-20}$. Drager and colleagues reported no evidence of circadian rhythm in PWV at four time points (08h00, 12h00, $16 \mathrm{~h} 00$ and 20h00), though in a small population $(n=15)^{20}$. Other groups studied diurnal variability at fewer time-points, Ter Avest et $\mathrm{al}^{18}$ on two occasions (09h00 and 14h00) and Yanlei et al ${ }^{19}(\mathrm{n}=70)$ on three $(09 \mathrm{~h} 00$, $13 \mathrm{~h} 00$ and 17h00), and reported no diurnal variation in PWV. For the non-invasive CO using the $\mathrm{NICOM}^{\circledast}$, the statistically significant higher mean $\mathrm{CO}$ in the afternoon conforms to the normal expected physiological variation. The lack of diurnal variability in arterial stiffness parameters is important to determine, as the lack of standardisation of measurements by

time of day has been previously criticised ${ }^{24-26}$. In addition, we can be confident of a lack of diurnal variability as measurements were performed at four time points in a day, compared to other studies which used longer intervals ${ }^{18,19}$. Also, the present study population for the diurnal variation study $(n=21)$ was adequately powered to assess for any biologically important changes amongst this population group. Nonetheless, it is vital that all other 
determinants such as maternal age, $\mathrm{HR}$ and $\mathrm{MAP}^{27}$ be carefully evaluated and adjusted for accordingly.

The repeatability study findings are also consistent with previous work carried out in nonpregnant women ${ }^{19,21,22}$. Yanlei and colleagues examined changes in 7 subjects and reported that the coefficient of variation (CV) of the two repeated measurements of PWV, 5 minutes apart, was $6.1 \%$ with the absolute difference for the repeated measures being $-0.151 \mathrm{~m} / \mathrm{s}$ $(95 \% \mathrm{Cl}:-2.022-1.720)^{19}$. Baulman et $\mathrm{al}^{21}$ validated measurements of arterial stiffness between an oscillometric (Arteriograph ${ }^{\circledR}$ ), tonometric (SphygmoCor) and piezo-electronic methods $\left(\right.$ Complior $\left.^{\circledR}\right)$. The authors observed that the variance within one session was the

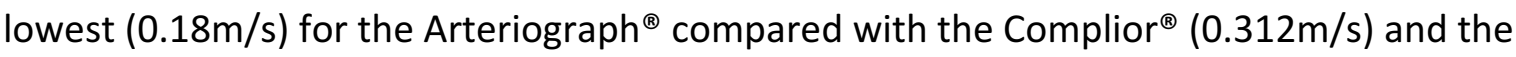
SphygmoCor ${ }^{\circledast}(0.363 \mathrm{~m} / \mathrm{s}$,$) . Importantly, we only looked at the repeatability of$ measurements within a single visit, whereas Baulman et $\mathrm{al}^{21}$ evaluated the trend further by looking at the reproducibility of measurements between two sessions, undertaken one week apart. They found the measurement errors for the repeat measurements' were also the lowest for the Arteriograph ${ }^{\circledR}(1.18 \mathrm{~m} / \mathrm{s})$, as compared to the Complior ${ }^{\circledR}(1.55 \mathrm{~m} / \mathrm{s})$ and the SphygmoCor ${ }^{\circledR}(1.67 \mathrm{~m} / \mathrm{s})$. In the present study, we only assessed repeatability of measurements within a single visit, so as to reduce the possible bias of advancing gestation on maternal haemodynamics.

One limitation of the present study was that assessments were confined to the third trimester of pregnancy. Over the first two trimesters of pregnancy, CO gradually increases with the greatest increase occurring by 16 weeks of gestation. The rise in CO typically plateaus after 20 weeks of gestation but remains at that elevated level until the term ${ }^{28}$. 
Therefore, we intentionally chose to evaluate the circadian rhythm of $\mathrm{CO}$ and arterial stiffness in women in their third trimester. In addition, our inclusion criteria aimed to reduce the influence of a maternal age range on the haemodynamic parameters as Khalil et al ${ }^{29}$ have demonstrated that PWV and systolic BP have a directly proportional relationship to maternal age. It is also important to stress that diurnal variations reported in the present study pertained to young healthy low-risk pregnant women in their third trimester. Therefore, these conclusions may not be valid for women in the first two trimesters or patients with pregnancy complications or co-morbidity. Slightly lower estimates of ICC for Arteriograph measurements also suggest that a study with bigger sample size might be warranted to consider higher variabilities for these measurements.

\section{CONCLUSION}

With the exception of $\mathrm{CO}$, diurnal measurements of these variables in young healthy lowrisk pregnant women in their third trimester did not change significantly from morning to midnight. Multiple consecutive measurements of vascular stiffness and non-invasive CO measurements on the same woman in the third trimester of pregnancy were highly correlated, confirming excellent repeatability of measurements. Given the increase in the use of non-invasive haemodynamic monitors, results have great implications for clinical research and application in clinical practice. We propose that it is not mandatory to measure PWV and Alx at the same time of day. However, standardising the time of day for noninvasive cardiovascular assessment may be beneficial in longitudinal studies. Further work is required to evaluate the diurnal variation in high-risk pregnancies such as those complicated by diabetes, hypertension and other cardiac risk factors. 


\section{REFERENCES}

1. Edouard DA, Pannier BM, London GM, Cuche JL, Safar ME. Venous and arterial behavior during normal pregnancy.. Am J Physiol. 1998;274:1605.

2. Hunter S RS. Adaptation of the maternal heart in pregnancy. Br Heart J. 1992;68:540.

3. Robson SC, Hunter S, Boys RJ, et al. Serial study of factors influencing changes in cardiac output during human pregnancy. Am J Physiol. 1989;256:1060-1065.

4. Duvekot JJ, Cheriex EC, Pieters FA, Menheere PP, Peeters LH. Early pregnancy changes in hemodynamics and volume homeostasis are consecutive adjustments triggered by a primary fall in systemic vascular tone. Am J Obstet Gynecol. 1993;169:1382-1392.

5. Robson SC, Hunter S, Boys RJ, Dunlop W. Serial study of factors influencing changes in cardiac output during human pregnancy. Am J Physiol. 1989;256:1060-1065.

6. Tihtonen KM, Koobi T, Uotila JT. Arterial stiffness in preeclamptic and chronic hypertensive pregnancies. . Eur J Obstet Gynecol Reprod Biol. 2006;128:180.

7. Ronnback M, Lampinen K, Groop PH, Kaaja R. Pulse wave reflection in currently and previously preeclamptic women.

. Hypertens Pregnancy. 2005;24:171.

8. Hausvater A, Giannone T, Sandoval YH, et al. The association between preeclampsia and arterial stiffness. J Hypertens. 2012;30(1):17-33. doi: 10.1097/HJH.0b013e32834e4b0f [doi].

9. Khalil A, Sodre D, Syngelaki A, Akolekar R, Nicolaides KH. Maternal hemodynamics at 11-13 weeks of gestation in pregnancies delivering small for gestational age neonates. Fetal Diagn Ther. 2012;32(4):231-8-Epub 2012 Sep 25. 
10. Osman M.W, Nath M, Breslin E.J, Khalil A, Webb D.R, Robinson T.G, Mousa H.A. Arterial stiffness measurements as a screening tool for placental mediated diseases in pregnancy: Findings of a systematic review and meta-analysis. Ultrasound in obstetrics \& gynecology : the official journal of the International Society of Ultrasound in Obstetrics and Gynecology. 2016;In press:Poster presentation.

11. Laurent S, Cockcroft J, Van Bortel L, et al. Expert consensus document on arterial stiffness: Methodological issues and clinical applications. Eur Heart J. 2006;27:2588-2605.

12. Vlachopoulos C, Aznaouridis K, Stefanadis C. Prediction of cardiovascular events and all-cause mortality with arterial stiffness: A systematic review and meta-analysis. J Am Coll Cardiol. 2010;55:1318-1327.

13. Blacher J, Guerin AP, Pannier B, Marchais SJ, Safar ME, London GM. Impact of aortic stiffness on survival in end-stage renal disease. Circulation. 1999;99:2434-2439.

14. Laurent S, Boutouyrie P, Asmar R, Gautier I, Laloux B, Guize L, Ducimetiere P, Benetos A. Aortic stiffness is an independent predictor of all-cause and cardiovascular mortality in hypertensive patients. Hypertension. 2001;37:1236-1241.

15. Cruickshank, K., Riste, L., Anderson, S. G., Wright, J. S., Dunn, G. and Gosling, R. G. Aortic pulsewave velocity and its relationship to mortality in diabetes and glucose intolerance: An integrated index of vascular function? Circulation. 2002;106:2085-2090.

16. Sutton-Tyrrell, K., Najjar, S. S., Boudreau, R. M. Elevated aortic pulse wave velocity, a marker of arterial stiffness, predicts cardiovascular events in well-functioning older adults. Circulation. 2005;111:3384-3390. 
17. Mancia G, De Backer G, Dominiczak A, Cifkova R, Fagard R, Germano G, Grassi G, Heagerty AM, Kjeldsen SE, Laurent S, Narkiewicz K, Ruilope L, Rynkiewicz A, Schmieder RE, Struijker Boudier HA, Zanchetti A, Vahanian A, Camm J, De Caterina R, Dean V, Dickstein K, Filippatos G, Funck-Brentano C, Hellemans I, Kristensen SD, McGregor K, Sechtem U, Silber S, Tendera M, Widimsky P, Zamorano JL, Erdine S, Kiowski W, Agabiti-Rosei E, Ambrosioni E, Lindholm LH, Manolis A, Nilsson PM, Redon J, Struijker-Boudier HA, Viigimaa M, Adamopoulos S, Bertomeu V, Clement D, Farsang C, Gaita D, Lip G, Mallion JM, Manolis AJ, O'Brien E, Ponikowski P, Ruschitzka F, Tamargo J, van Zwieten P, Waeber B, Williams B,. The task force for the management of arterial hypertension of the european society of $\mathrm{H}$, the task force for the management of arterial hypertension of the european society of C. 2007 guidelines for the management of arterial hypertension: The task force for the management of arterial hypertension of the european society of hypertension (ESH) and of the european society of cardiology (ESC). Eur Heart J. 2007;28(1):462-1536.

18. Ter Avest E, Holewijn S, Stalenhoef AF. Variation in non-invasive measurements of vascular function in healthy volunteers during daytime. Clin Sci (Lond). 2005;108(5):425.

19. Yanlei Li, Mareike Cordes, Jose I Recio-Rodriguez, Luis Garcia-Ortiz,Henner Hanssen and Arno Schmidt-Trucks Ä SS. Diurnal variation of arterial stiffness in healthy individuals of different ages and patients with heart disease. Scandinavian Journal of Clinical \& Laboratory Investigation. 2014;74:155.

20. Luciano F. Drager, Luzia Diegues-Silva, Patrı́cia M. Diniz, MS, Geraldo Lorenzi-Filho, Eduardo M. Krieger, Luiz A. Bortolotto,. Lack of circadian variation of pulse wave velocity measurements in healthy volunteers. J Clin Hypertens. 2011;13:19. 
21. Baulmann J, Schillings U, Rickert S, Uen S, Dusing R, Illyes M, Cziraki A, Nickenig G and Mengden T. A new oscillometric method for assessment of arterial stiffness: Comparison with tonometric and piezo-electronic methods. Journal of Hypertension. 2008;26:523.

22. Meyer ML, Tanaka H, Palta P, Patel MD, Camplain R, Couper D, Cheng S, Al Qunaibet A, Poon AK, Heiss G. Repeatability of central and peripheral pulse wave velocity measures: The atherosclerosis risk in communities (ARIC) study. Am J Hypertens. 2016;29(4):470.

23. R Core Team. R: A language and environment for statistical computing. Vienna, Austria. 2016.

24. Marina Cecelja PC. Dissociation of aortic pulse wave velocity with risk factors for cardiovascular disease other than hypertension: A systematic review. Hypertension. 2009;54:1328.

25. Weber T, Auer J, O'Rouke MF, Kvas E, Lassnig, E, Berent R. Arterial stiffness, wave reflection and the risk of coronary artery disease. Circulation. 2004;109:184.

26. Brown Y BM. Similarities and differences between augmentation index and pulse wave velocity in the assessment of arterial stiffness. QJM. 1999;92:595.

27. Macedo M.L, Luminoso D, Savvidou M.D, McEniery C.M, Nicolaides K.H. Maternal wave reflections and arterial stiffness in normal pregnancy as assessed by applanation tonometry. Hypertension. 2008;51:1047-1051.

28. Ruys TP, Cornette J, Roos-Hesselink JW. Pregnancy and delivery in cardiac disease. J Cardiol 2013. 2013;61:107-112.

29. Khalil A, Akolekar R, Syngelaki A, Elkhouli M, Nicolaides KH. Maternal hemodynamics in normal pregnancies at 11-13 weeks' gestation. Fetal Diagn Ther. 2012;32:179-185. 


$$
\text { . }
$$


Table 1: Estimates of mean (standard deviation) of maternal characteristics of participants in the diurnal variation and repeatability study.

\begin{tabular}{|l|c|c|}
\hline & Value & Value \\
& $(\mathbf{n = 2 1 )}$ & $31.57(6.09)$ \\
\hline Maternal age (years) & $28.95(6.38)$ & $1.86(0.19)$ \\
\hline Maternal body surface area $\left(\mathrm{m}^{2}\right)$ & $1.62(0.18)$ & $161.42(6.42)$ \\
\hline Maternal height $(\mathrm{cm})$ & $158.4(7.75)$ & $75.61(18.68)$ \\
\hline Maternal weight $(\mathrm{kg})$ & $57.41(10.41)$ & $28.68(6.49)$ \\
\hline Maternal body mass index $\left(\mathrm{kg} / \mathrm{m}^{2}\right)$ & $22.62(2.91)$ & $27.70(2.29)$ \\
\hline Gestational age (weeks) & $34.14(3.74)$ & \\
\hline
\end{tabular}


Table 2: Estimates of mean, standard deviation and intraclass correlation coefficients of arterial stiffness and cardiac output measurements

at four time points (morning, afternoon, evening, midnight) for 21 low risk patients.

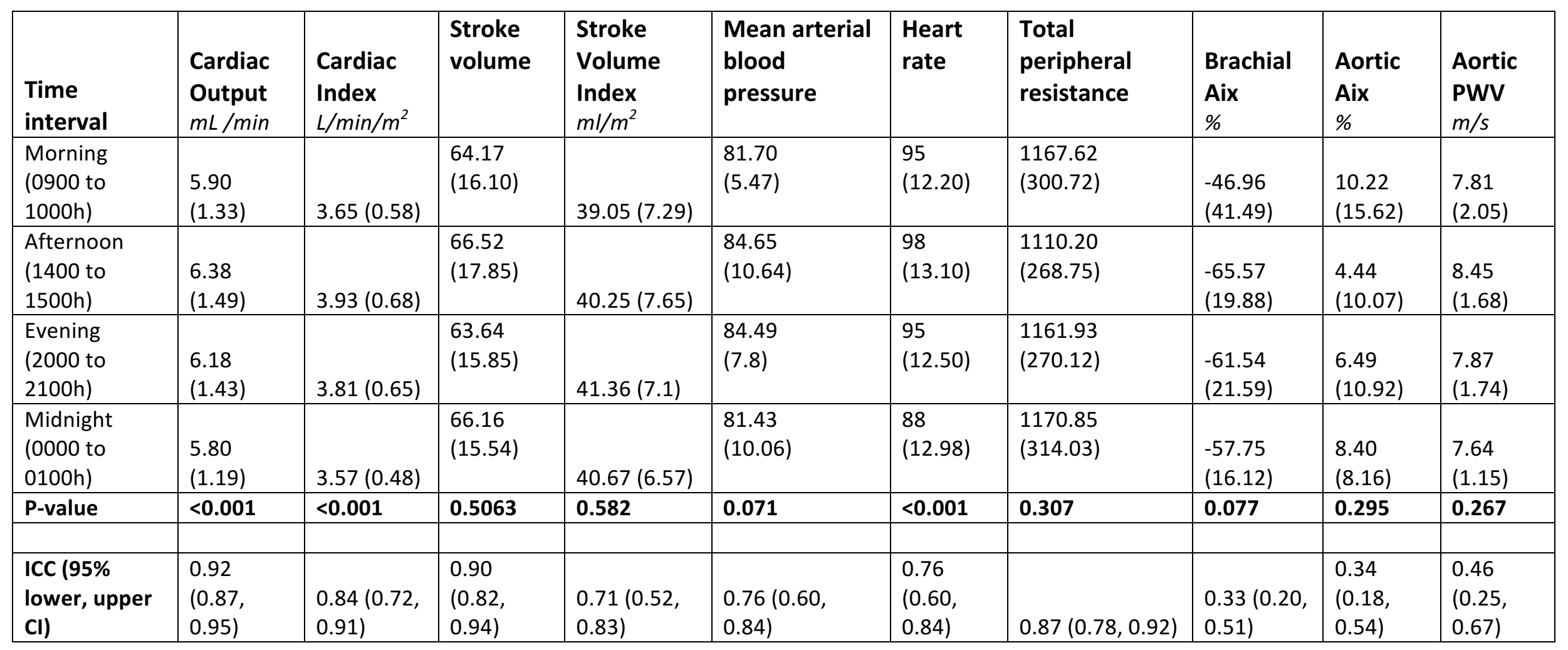


Table 3: Estimates of mean, standard deviation and intraclass correlation coefficients of arterial stiffness and cardiac output measurements at three replicates for 67 subjects.

\begin{tabular}{|c|c|c|c|c|c|c|c|}
\hline $\begin{array}{l}\text { Indices } \\
\text { (Unit) }\end{array}$ & $\begin{array}{l}\text { Cardiac } \\
\text { Output } \\
\mathrm{mL} / \mathrm{min}\end{array}$ & $\begin{array}{l}\text { Cardiac Index } \\
\mathrm{L} / \mathrm{min} / \mathrm{m}^{2}\end{array}$ & $\begin{array}{l}\text { Stroke } \\
\text { volume } \\
\mathrm{ml}\end{array}$ & $\begin{array}{l}\text { Stroke } \\
\text { Volume } \\
\text { Index } \\
\mathrm{ml} / \mathrm{m}^{2}\end{array}$ & $\begin{array}{l}\text { Brachial Alx } \\
\%\end{array}$ & $\begin{array}{l}\text { Aortic Alx } \\
\%\end{array}$ & $\begin{array}{l}\text { Aortic } \\
\text { PWV } \\
\mathrm{m} / \mathrm{s}\end{array}$ \\
\hline$(n=67)$ & $7.37(1.49)$ & $3.97(0.57)$ & $82.95(18.67)$ & $\begin{array}{l}44.27 \\
(8.44) \\
\end{array}$ & $-64.6(20.85)$ & $4.32(8.40)$ & $\begin{array}{l}8.11 \\
(1.56) \\
\end{array}$ \\
\hline \multicolumn{8}{|l|}{ Time } \\
\hline $\begin{array}{l}\text { Time } 1 \\
\text { (0 min) }\end{array}$ & $7.43(1.50)$ & $3.99(0.59)$ & 83.25 (18.98) & 44.4 (7.99) & $-65.78(17.69)$ & $4.09(8.87)$ & $8.14(1.53)$ \\
\hline $\begin{array}{l}\text { Time } 2 \\
\text { (5 min) }\end{array}$ & $7.28(1.61)$ & $3.97(0.58)$ & $82.59(19.03)$ & $\begin{array}{l}44.31 \\
(8.36) \\
\end{array}$ & $-66.84(16.39)$ & $3.80(8.30)$ & $8.09(1.28)$ \\
\hline $\begin{array}{l}\text { Time } 3 \\
(10 \mathrm{~min})\end{array}$ & $7.39(1.35)$ & $3.97(0.56)$ & $83(18.27)$ & $44.1(9.07)$ & $-60.85(27.31)$ & $5.15(8.03)$ & $8.11(1.86)$ \\
\hline P-value & 0.756 & 0.708 & 0.818 & 0.686 & 0.136 & 0.450 & 0.638 \\
\hline $\begin{array}{l}\text { ICC ( } 95 \% \text { lower, } \\
\text { upper } \mathrm{CI})\end{array}$ & $\begin{array}{l}0.80(0.62, \\
0.90)\end{array}$ & $0.78(0.64,0.85)$ & $\begin{array}{l}0.91(0.85, \\
0.94)\end{array}$ & $\begin{array}{l}0.80(0.63, \\
0.89)\end{array}$ & $\begin{array}{l}0.49(0.23, \\
0.76)\end{array}$ & $\begin{array}{l}0.67(0.40, \\
0.83)\end{array}$ & $0.79(0.58,0.91)$ \\
\hline
\end{tabular}



Figure 1: Measurements of Arteriograph and NICOM variables of 21 patients (points) at four time points (morning, afternoon, evening and midnight) with the corresponding box plots showing the median and interquartile range

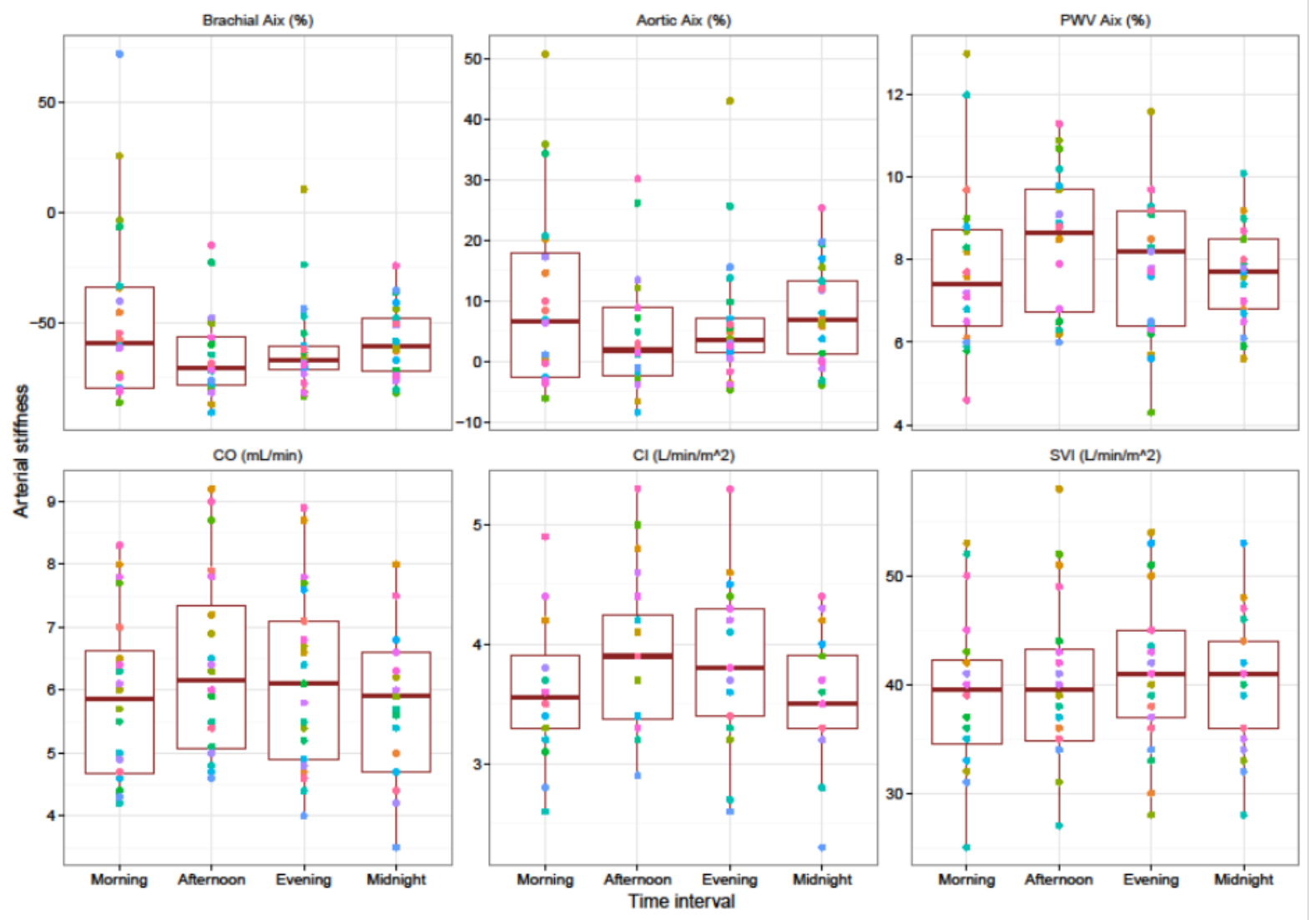

$\mathrm{Br}$ Aix: Brachial augmentation index; Ao Aix: Aortic augmentation index; Ao PWV: Aortic pulse wave velocity; CO: Cardiac output; $\mathrm{Cl}$ : Cardiac Index; SVI: Stroke volume index

Points with the same colour represent data from the same patient. 
Figure 2: Measurements of Arteriograph ${ }^{\circledR}$ and NICOM $^{\circledR}$ variables of all 67 patients (points) over three successive measurements $(1,2,3)$ where triplicate measurements on the same patient are joined by dotted lines to demonstrate the consistency in repeatable measurements. The bold red line connects the mean values at each of the measurement points.
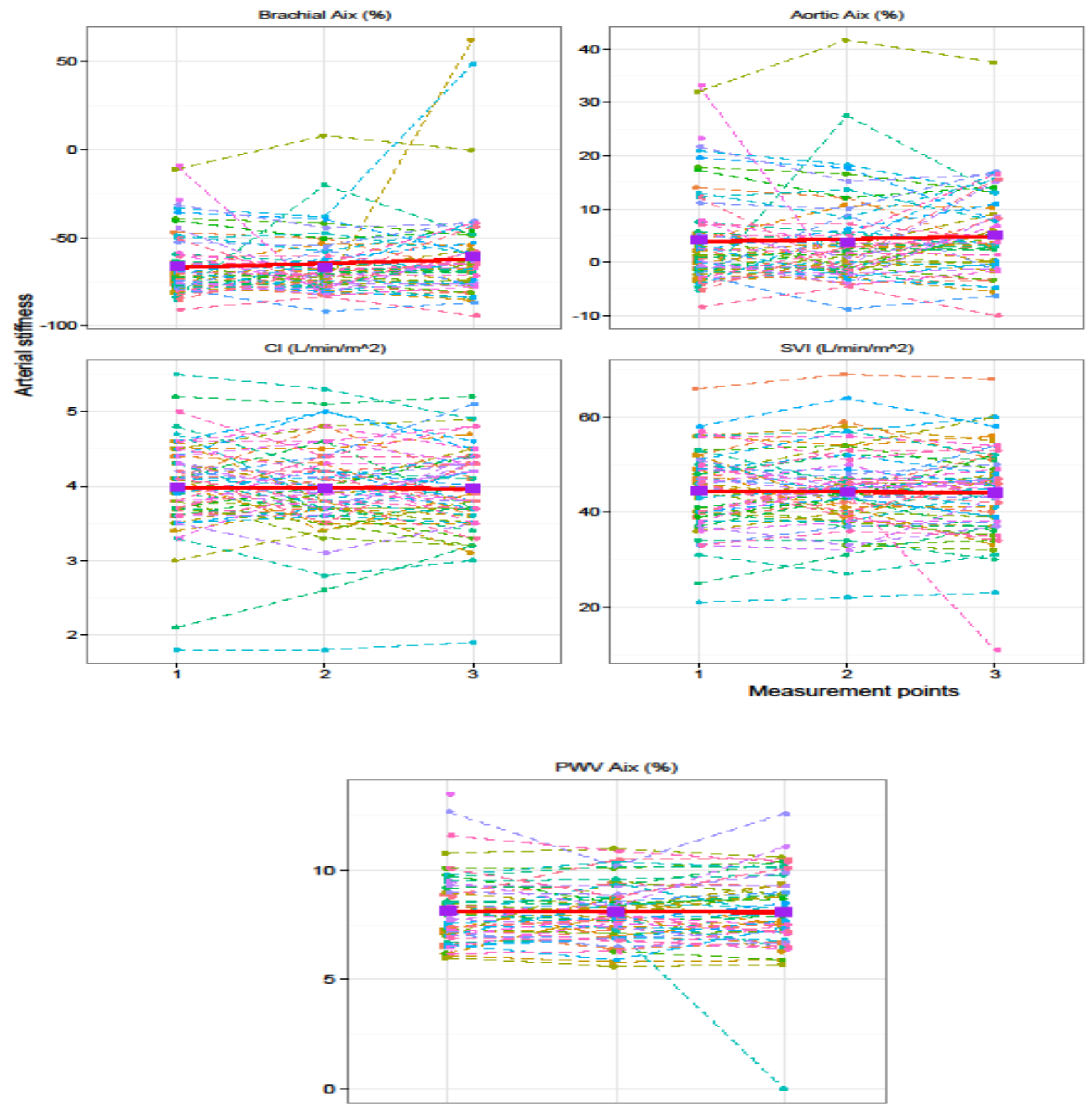

Points and lines with the same colour represent data from the same patient. 
Figure 3: Measurements of Arteriograph ${ }^{\circledR}$ and NICOM ${ }^{\circledR}$ variables of all 67 patients (points) over three successive measurements $(1,2,3)$ along with the corresponding box plots showing the median and interquartile range
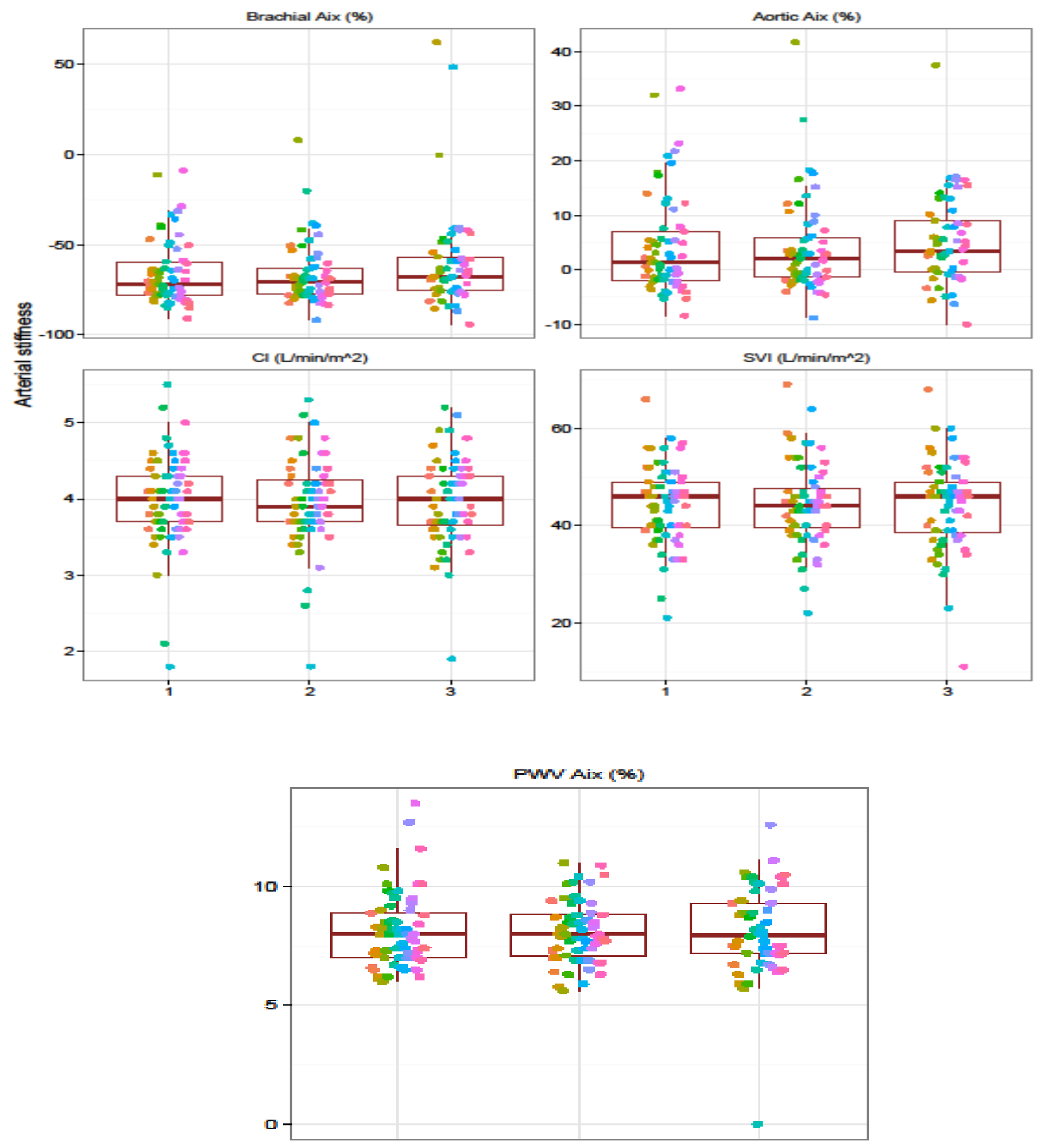

Br Aix: Brachial augmentation index; Ao Aix: Aortic augmentation index; Ao PWV: Aortic pulse wave velocity; CO: Cardiac output; Cl: Cardiac Index; SVI: Stroke volume index.

Points with the same colour represent data from the same patient. 